\title{
Oxidized Albumin Triggers a Cytokine Storm in Leukocytes Through P38 Mitogen-Activated Protein Kinase: Role in Systemic Inflammation in Decompensated Cirrhosis
}

\author{
José Alcaraz-Quiles, ${ }^{1}$ Mireia Casulleras, ${ }^{1}$ Karl Oettl,${ }^{2}$ Esther Titos, ${ }^{1,3}$ Roger Flores-Costa,,${ }^{1}$ Marta Duran-Güell, ${ }^{1}$ \\ Cristina López-Vicario, ${ }^{1,3}$ Marco Pavesi, ${ }^{4}$ Rudolf E. Stauber, ${ }^{5}$ Vicente Arroyo, ${ }^{4}$ and Joan Clària ${ }^{1,3,4,6}$
}

\begin{abstract}
Decompensated cirrhosis is characterized by exuberant systemic inflammation. Although the inducers of this feature remain unknown, the presence of circulating forms of oxidized albumin, namely human nonmercaptalbumin 1 (HNA1) and HNA2, is a common finding in cirrhosis. The aim of this study was to explore the ability of these oxidized albumin forms to induce systemic inflammation by triggering the activation of peripheral leukocytes. We observed significantly higher plasma levels of HNA1 and HNA2 in patients with cirrhosis $(n=256)$ compared to healthy volunteers $(n=48)$, which gradually increased during the course from compensated to decompensated to acute-on-chronic liver failure. Plasma HNA1 and HNA2 levels significantly correlated with inflammatory markers (i.e., interleukin-6 [IL-6], IL-1 $\beta$, tumor necrosis factor-alpha $[\mathrm{TNF}-\alpha]$ and IL-8) in patients with cirrhosis. To directly test the inflammatory effects of HNA1 and HNA2 on leukocytes, these oxidized albumin forms were prepared ex vivo and their posttranslational modifications monitored by liquid chromatography (LC)-quadrupole time-of-flight/mass spectrometry (MS). HNA1, but not HNA2, increased IL-1 $\beta$, IL-6, and TNF- $\alpha$ mRNA and protein expression in leukocytes from both healthy volunteers and patients with cirrhosis. Moreover, HNA1 upregulated the expression of eicosanoid-generating enzymes (i.e., cyclooxygenase-2 [COX-2] and microsomal prostaglandin $\mathrm{E}[\mathrm{PGE}]$ synthase 1$)$ and the production of inflammatory eicosanoids $\left(\mathrm{PGE}_{2}, \mathrm{PGF}_{2 \alpha}\right.$, thromboxane $\mathrm{B}_{2}$, and leukotriene $\mathrm{B}_{4}$ ), as determined by LC-electrospray ionization-MS/MS. The inflammatory response to HNA1 was more pronounced in peripheral blood mononuclear cells (PBMCs) and marginal in polymorphonuclear neutrophils. Kinome analysis of PBMCs revealed that HNA1 induced the phosphorylation of p38 mitogen-activated protein kinase, the inhibition of which blocked HNA1-induced cytokine and COX-2 induction. Conclusion: HNA1 triggers an inflammatory response in PBMCs, providing a rationale for its removal and replacement by reduced albumin in the prevention of systemic inflammation in patients with advanced liver disease. (Hepatology 2018;0:1-16).
\end{abstract}

$\mathrm{S}$

ystemic inflammation characterized by an cytokines, lipid mediators, and acute-phase proteins increased white blood cell (WBC) count and (C-reactive protein, fibrinogen, and ferritin) is a hallincreased circulating levels of inflammatory mark of decompensated cirrhosis (DC) ${ }^{(1-3)}$ Moreover,

Abbreviations: $A C L F$, acute-on-chronic liver failure; $A D$, acute decompensation; $C C$, compensated cirrbosis; $C L I F$, chronic liver failure; $C O X$, cyclooxygenase; $D C$, decompensated cirrhosis; ERK, extracellular signal-regulated kinase; ESI, electrospray ionization; G-CSF, granulocyte colonystimulating; HCV, hepatitis $C$ virus; HETE, hydroxyeicosatetraenoic acid; HMA, human mercaptalbumin; HNA, human nonmercaptalbumin; HPLC, high-performance liquid chromatography; HRMS, high-resolution mass spectrometry; HSA, human serum albumin; HV, healthy volunteer; $I L$, interleukin; $I L-1 r a, I L-1$ receptor antagonist; 5-LOX, 5-lipoxygenase; LT, leukotriene; MAP, mitogen-activated protein; MELD, Model for End-Stage Liver Disease; MIP-1 $\alpha$, macrophage inflammatory protein-1 alpha; mPGES-1, microsomal prostaglandin E synthase 1; MS, mass spectrometry; PBMC, peripheral blood mononuclear cell; PG, prostaglandin; PMN, polymorphonuclear neutrophil; qTOF, quadrupole time-offlight; $R N S$, reactive nitrogen species; ROS, reactive oxygen species; $S A H$, severe alcoholic hepatitis; $S R$, scavenger receptor; TNF- $\alpha$, tumor necrosis factor-alpha; TX, thromboxane.

Received January 12, 2018; accepted May 20, 2018

Additional Supporting Information may be found at onlinelibrary.wiley.com/doi/10.1002/hep.30135/suppinfo. 
systemic inflammation together with oxidative stress play a major role in the pathogenesis of acute-onchronic liver failure (ACLF), an increasingly recognized clinical entity characterized by the appearance of multiple organ failure and high mortality in patients with DC. ${ }^{(1-4)}$ In general terms, the degree of systemic inflammation in cirrhosis increases in parallel to disease severity, being moderate in patients with compensated cirrhosis (CC) and intense in patients with DC, especially in those developing ACLF. ${ }^{(1,2)}$ Although decompensation of cirrhosis frequently occurs in the context of precipitating events, mainly active alcoholism/acute alcoholic hepatitis or bacterial infections, ${ }^{(2,5)}$ in a significant proportion of patients, the triggering factor or the precipitating event responsible for the abrupt increase in systemic inflammation remains unknown.

Albumin is the most abundant protein in human plasma, playing important roles as a plasma expander and transporter of fatty acids and in drug binding, metal chelation, and free radical scavenging. ${ }^{(6)}$ Indeed, albumin is the main antioxidant protein in plasma, a feature that is - at least in part-mediated by the antioxidant properties of its free thiol moiety at cysteine $34{ }^{(7)}$ Because albumin is exclusively produced by the liver, its synthesis is compromised in patients with cirrhosis, in whom liver function is deteriorated. ${ }^{(8)}$ Consequently, patients with cirrhosis commonly show reduced circulating levels of albumin. ${ }^{(6,8)}$ In addition to hypoalbuminemia, patients with advanced liver disease have a higher content of severely oxidized forms of albumin. ${ }^{(1,9,10)}$ In particular, oxidation of reduced albumin (human mercaptalbumin [HMA]) in cirrhosis leads to posttranslational modifications in its molecule, resulting in human nonmercaptalbumin 1 (HNA1) and HNA2. Increased circulating levels of HNA1 and HNA2 are common in patients with $\mathrm{CC}$ and more pronounced in patients with DC. In clinical practice, circulating levels of HNA1 and HNA2 in plasma or serum are currently used as systemic markers of oxidative stress in patients with cirrhosis. ${ }^{(1,9,10)}$ Although oxidized albumin forms (i.e., HNA1 and HNA2) have reduced binding capacity and lack the ability to effectively remove circulating toxic and pro-oxidant substances, ${ }^{(7,10)}$ at present, it is not fully established whether these oxidized albumin forms are mostly inactive or possess some not yet characterized biological properties. The hypothesis of our investigation was that HNA1 and HNA2 may act as activators of peripheral leukocytes, enhancing the degree of systemic inflammation in patients with advanced liver disease.

\section{Patients and Methods}

\section{PATIENTS}

The study included 48 healthy volunteers (HVs); 31 ambulatory patients with $\mathrm{CC}$, who had never presented acute decompensation (AD); 153 patients

Supported by Spanish Ministerio de Economía y Competitividad (SAF15/63674-R and PIE14/00045) under European Regional Development Funds and by an Agaur/BFU fellowship (FI-DGR 2015, to J.A.-Q.). CIBERebd is funded by the Instituto de Salud Carlos III. Our laboratory is a Consolidated Research Group recognized by the Generalitat de Catalunya (2017SGR1449).

(C) 2018 by the American Association for the Study of Liver Diseases.

View this article online at wileyonlinelibrary.com.

DOI 10.1002/hep.30135

Potential Conflict of Interest: Nothing to report.

\section{ARTICLE INFORMATION:}

From the ${ }^{1}$ Department of Biochemistry and Molecular Genetics, Hospital Clínic-IDIBAPS, Barcelona, Spain; ${ }^{2}$ Institute of Physiological Chemistry, Center of Physiological Medicine, Medical University of Graz, Graz, Austria; ${ }^{3}$ Centro de Investigación Biomédica en Red de Enfermedades Hepáticas y Digestivas (CIBERehd), Barcelona, Spain; ${ }^{4}$ European Foundation for the Study of Chronic Liver Failure (EF-CLIF), Barcelona, Spain; ${ }^{5}$ Division of Gastroenterology and Hepatology, Department of Internal Medicine, Medical University of Graz, Graz, Austria; ${ }^{6}$ Department of Biomedical Sciences, University of Barcelona, Barcelona, Spain.

\section{ADDRESS CORRESPONDENCE AND REPRINT REQUESTS TO:}

Joan Clària, Ph.D.

Department of Biochemistry and Molecular Genetics

Hospital Clínic, Villarroel 170
Barcelona 08036, Spain

E-mail: jclaria@clinic.cat

Tel.: +34-93-2255400 ext. 4784 
with DC; and 72 patients with DC and ACLF. DC patients with and without ACLF at hospital admission were selected from the CANONIC study of the Chronic Liver Failure (CLIF) Consortium and were without a known precipitating event. In the CANONIC study, hospitalized patients with an $\mathrm{AD}$ of cirrhosis (i.e., ascites, gastrointestinal bleeding, hepatic encephalopathy, bacterial infections, or any combination of these) were screened and enrolled from February to September 2011 in 29 university hospitals from 8 European countries. ${ }^{(2)}$ In the CANONIC study, ACLF was defined as an AD resulting in liver failure and/or one or more extrahepatic organ failures in patients with chronic liver disease with or without previously diagnosed cirrhosis. The diagnostic criteria for organ failure was defined according to the Sequential Organ Failure Assessment-CLIF score.

\section{MEASUREMENT OF CIRCULATING ALBUMIN LEVELS AND THEIR OXIDIZED FORMS IN HVS AND PATIENTS WITH CIRRHOSIS}

Albumin fractions were separated by high-performance liquid chromatography (HPLC) and detected by fluorescence as described. ${ }^{(11,12)}$ More details are given in the Supporting Information.

\section{EX VIVO PREPARATION OF ALBUMIN AND OXIDIZED FORMS FOR IN VITRO EXPERIMENTS}

HMA, HNA1, and HNA2 were prepared from $15 \mathrm{~mL}$ of plasma from healthy donors (a 34-yearold woman and a 54-year-old man). Plasma aliquots $(1.5 \mathrm{~mL})$ were equilibrated $\left(50 \mathrm{mM} \mathrm{KH}_{2} \mathrm{PO}_{4}\right.$, $\mathrm{pH} 7.0)$ and eluted $\left(50 \mathrm{mM} \mathrm{KH} \mathrm{PO}_{4}, 1.5 \mathrm{M} \mathrm{KCl}\right.$, $\mathrm{pH}$ 7.0) through a HiTrap Blue HP column (GE Healthcare Life Sciences, Piscataway, NJ) for fractioning and dialyzed several times against phosphate-buffered saline (PBS). To obtain HNA1, the dialyzed albumin was incubated with cystine (17 $\mathrm{mM})$ at $37^{\circ} \mathrm{C}$ for at least 24 hours. HNA2 was prepared by incubating the dialyzed albumin with $\mathrm{H}_{2} \mathrm{O}_{2}$ (45 mM) for 1 hour at room temperature. Finally, the three fractions were applied to a PD-10 desalting column (GE Healthcare) to remove salts, residual cystine, or $\mathrm{H}_{2} \mathrm{O}_{2}$ and eluted with $\mathrm{PBS}$ prior to being lyophilized. The redox state of the collected fractions was further assessed by HPLC. The results obtained in this analysis were as follows: HMA fraction, $85 \%$ HMA, 12\% HNA1, and 3\% HNA2; HNA1 fraction, 0\% HMA, 97\% HNA1, and 3\% HNA2; and HNA2 fraction, 6\% HMA, 9\% HNA1, and 86\% HNA2. For in vitro experiments, lyophilized albumin fractions were reconstituted with Roswell Park Memorial Institute 1640 medium containing penicillin (100 $\mathrm{U} / \mathrm{mL})$, streptomycin $(100 \mathrm{U} / \mathrm{mL})$, and L-glutamine (4 mM) without fetal bovine serum; filtered; and stored at $-80^{\circ} \mathrm{C}$ until use.

\section{ANALYSIS OF POSTTRANSLATIONAL ALBUMIN MODIFICATIONS BY MASS SPECTROMETRY}

To check modifications in albumin levels, intact mass analysis was carried out by LC coupled to quadrupole time-of-flight (qTOF) high-resolution mass spectrometry (HRMS) in a 1290 Infinity UHPLC and 6550 qTOF (both from Agilent Technologies, Santa Clara, CA). The chromatographic column was an Agilent Zorbax-SB C8 $(2.1 \times 30 \mathrm{~mm}, 3.5 \mu \mathrm{m})$, and the elution was carried out by gradient elution using ultra-pure water and acetonitrile (Merck), both with 0.5\% formic acid (Sigma-Aldrich Company, St Louis, MO) as the mobile phase. The albumin fractions were diluted at $0.1 \mathrm{mg} / \mathrm{mL}$ with water $(0.1 \%$ formic acid $)$ and maintained at $4{ }^{\circ} \mathrm{C}$ for analysis. Ionization was by positive electrospray $(5 \mathrm{kV}$ capillary voltage, desolvation temperature $400^{\circ} \mathrm{C}$, and flow rate $12 \mathrm{~L} /$ minute $\left[\mathrm{N}_{2}\right]$ ), and the mass spectrum was recorded between 1,000 and $2,500 \mathrm{~m} / \mathrm{z}$ at 0.5 spectra/second. The extracted average spectra of the chromatographic peak corresponding to albumin was deconvoluted using the maximum entropy algorithm of the Bioconfirm 6.0 module from Mass Hunter Software (Agilent Technologies). The relative abundance (percentage) of each isoform was calculated by dividing the abundance of each isoform by the sum of total intensities of all isoforms. The putative assignment of human serum albumin (HSA) isoforms was performed by the measured deconvoluted mass, allowing a maximum mass error of $\pm 10 \mathrm{Da}$, supported by the results of previous studies. $^{(13-16)}$ 


\section{ASSESSMENT OF REACTIVE OXYGEN SPECIES/REACTIVE NITROGEN SPECIES IN ALBUMIN FRACTIONS}

The OxiSelect In Vitro ROS/RNS Assay Kit (Cell Biolabs Inc., San Diego, CA) containing a specific reactive oxygen species/reactive nitrogen species (ROS/ RNS) probe, dichlorodihydrofluorescein DiOxyQ, was used to measure the total amounts of ROS/RNS by fluorescence in the reconstituted albumin fractions at concentrations of 1,5 , and $10 \mathrm{mg} / \mathrm{mL}$. More details are given in the Supporting Information.

\section{ANTIOXIDANT CAPACITY OF ALBUMIN FRACTIONS}

The total antioxidant capacity in the reconstituted albumin fractions at concentrations of 1,5 , and 10 $\mathrm{mg} / \mathrm{mL}$ was determined using the OxiSelect Total Antioxidant Capacity Assay Kit (Cell Biolabs Inc.). More details are given in the Supporting Information.

\section{DETERMINATION OF ENDOTOXIN LEVELS IN ALBUMIN FRACTIONS}

Endotoxin levels in ex vivo albumin preparations were subjected to a Limulus amebocyte lysate assay using a ToxinSensor Chromogenic LAL Endotoxin Assay Kit (GenScript, Piscataway, NJ).

\section{ISOLATION AND INCUBATION OF HUMAN PERIPHERAL BLOOD LEUKOCYTES}

Human peripheral blood cells were isolated from $20 \mathrm{~mL}$ of blood collected with ethylene diamine tetraacetic acid (EDTA) from healthy HVs (25 men [mean age, 47.8 years] and 17 women [mean age, 46.5 years]) recruited with informed consent from the Blood and Tissue Bank of the Hospital Clinic of Barcelona, as described. ${ }^{(17)}$ More details are given in the Supporting Information.

\section{MEASUREMENT OF CYTOKINE AND CHEMOKINE LEVELS}

Levels of interleukin (IL)-1 $\alpha$, IL-1 $\beta$, IL-6, IL-8, IL-7, tumor necrosis factor-alpha (TNF- $\alpha$ ), granulocyte colony-stimulating factor (G-CSF), macrophage inflammatory protein-1 alpha (MIP-1 $\alpha$ ), IL-10, and IL-1 receptor antagonist (IL-1ra) in plasma, leukocytes, and peripheral blood mononuclear cell (PBMC) supernatants were assessed in a Luminex 100 system (Luminex Corp., Austin, TX) using a custom-made MILLIPLEX MAP Human Cytokine/Chemokine Magnetic Bead Panel (Merck Millipore) (further details are given in the Supporting Information).

\section{RNA ISOLATION, REVERSE TRANSCRIPTION, AND REAL- TIME PCR}

Isolation of total RNA from leukocytes, PBMCs, and polymorphonuclear neutrophils (PMNs) was performed using the TRIzol reagent. RNA concentration was assessed in a NanoDrop-1000 spectrophotometer (NanoDrop Technologies) and its integrity tested with an RNA 6000 Nano Assay in a Bioanalyzer 2100 (Agilent Technologies). Complementary DNA (cDNA) synthesis from 0.5 to $1 \mu \mathrm{g}$ of total RNA was performed using the High-Capacity cDNA Archive Kit (Applied Biosystems, Foster City, CA). Details about real-time PCR analysis are given in the Supporting Information.

\section{PHOSPHO-KINASE ARRAY}

The initial screening of the phosphorylation status of 43 signaling molecules induced by albumin and their oxidized fractions was performed in a Proteome Profiler Human Phospho-Kinase Array Kit (R\&D Systems, Minneapolis, MN) (see Supporting Information).

\section{WESTERN BLOT ANALYSIS}

Total protein from PBMCs was extracted using a lysis buffer containing $50 \mathrm{mM}$ 4-(2-hydroxyethyl)-1-piperazine ethanesulfonic acid, $20 \mathrm{mM} \beta$-glycerophosphate, 2 mM EDTA, 1\% Igepal, 10\% glycerol, $1 \mathrm{mM} \mathrm{MgCl}_{2}, 1 \mathrm{mM} \mathrm{CaCl}_{2}$, and $150 \mathrm{mM} \mathrm{NaCl}$, supplemented with a mixture of protease (Complete Mini; Roche Diagnostics) and phosphatase (PhosSTOP; Roche Diagnostics) inhibitors. For protein isolation, the cells were homogenized in $100 \mu \mathrm{L}$ of lysis buffer and centrifuged at $1,000 \mathrm{~g}$ at $4^{\circ} \mathrm{C}$ for 10 minutes. 
Total protein $(10 \mu \mathrm{g})$ from supernatants was placed in sodium dodecyl sulfate (SDS)-containing Laemmli sample buffer heated at $95^{\circ} \mathrm{C}$ for 5 minutes and separated by $10 \%$ SDS-polyacrylamide gel electrophoresis for 90 minutes at $120 \mathrm{~V}$. Details about transfer and labeling with primary antihuman antibodies are given in the Supporting Information.

\section{ANALYSIS OF ARACHIDONIC ACID-DERIVED METABOLITES BY LC-ELECTROSPRAY IONIZATION- TANDEM MASS SPECTROMETRY}

Leukocyte supernatants $(200 \mu \mathrm{L})$ were spiked with an internal standard consisting of 15-hydroxyeicosatetraenoic acid with eight deuterium atoms (15-HETE-d8), leukotriene $\mathrm{B}_{4}\left(\mathrm{LTB}_{4}\right)$ with four deuterium ions, prostaglandin $\mathrm{E}_{2}\left(\mathrm{PGE}_{2}\right)$ with two deuterium ions (Cayman Chemical, Ann Arbor, MI) (5 ng each) in $500 \mu \mathrm{L}$ acetonitrile, $100 \mu \mathrm{L}$ water, and $5 \mu \mathrm{L}$ 2,6-di-tert-butyl-4-methylphenol $(10 \mathrm{mg} / \mathrm{mL})$ and shaken vigorously. Details and conditions used to profile arachidonic acid-derived metabolites by solid-phase extraction and HPLC-electrospray ionization (ESI)-tandem mass spectrometry (MS/MS) are given in the Supporting Information and Supporting Table S1.

\section{STATISTICAL ANALYSIS}

Results were compared using the unpaired Student $t$ test, one-way analysis of variance, Mann-Whitney U test, and Kruskal-Wallis test when applicable. To assess the relationship between two continuous variables, Spearman's rank correlation coefficient (Spearman's rho, $r_{\mathrm{s}}$ ) for nonparametric data was employed. Results were expressed as mean \pm SEM. Statistical analyses were performed using SPSS Statistics software (version 20.0; SPSS Science) and GraphPad Prism software (version 5; GraphPad Software, San Diego, CA). $P \leq 0.05$ was considered statistically significant.

\section{Results}

The characteristics of the patients included in the study are shown in Table 1 . No differences were observed in the age and gender of the patients with liver cirrhosis. Alcohol abuse and hepatitis $\mathrm{C}$ virus
TABLE 1. Patient Characteristics

\begin{tabular}{|c|c|c|c|}
\hline & CC & DC & ACLF \\
\hline & $(n=31)$ & $(n=153)$ & $(n=72)$ \\
\hline Age, years & $59.8 \pm 1.7$ & $58.4 \pm 0.9$ & $58.1 \pm 1.3$ \\
\hline Male, n (\%) & $18(58.1)$ & $97(63.4)$ & $48(66.7)$ \\
\hline \multicolumn{4}{|c|}{ Cause of cirrhosis, n (\%) } \\
\hline Alcohol & $7(22.6)$ & $59(38.6)$ & $33(45.8)$ \\
\hline $\mathrm{HCV}$ & $14(45.2)$ & $41(26.8)$ & $13(18.1)$ \\
\hline Alcohol + HCV & $0(0)$ & $12(7.8)$ & $8(11.1)$ \\
\hline Others & $10(32.2)$ & $41(26.8)$ & $18(25 \%)$ \\
\hline
\end{tabular}

Cause of hospitalization,

$\mathrm{n}(\%)$

Liver failure $\quad-\quad 19(12.4) \quad 29(40.3)^{\# \# \# ~}$

Renal failure $\quad-\quad 34(22.2) \quad 48(66.7)^{\# \# \# ~}$

Encephalopathy $\quad-\quad 49(32.0) \quad 43(59.7)^{\# \# \# ~}$

Ascites $\quad-\quad 84(54.9) \quad 55(76.4)^{\# \#}$

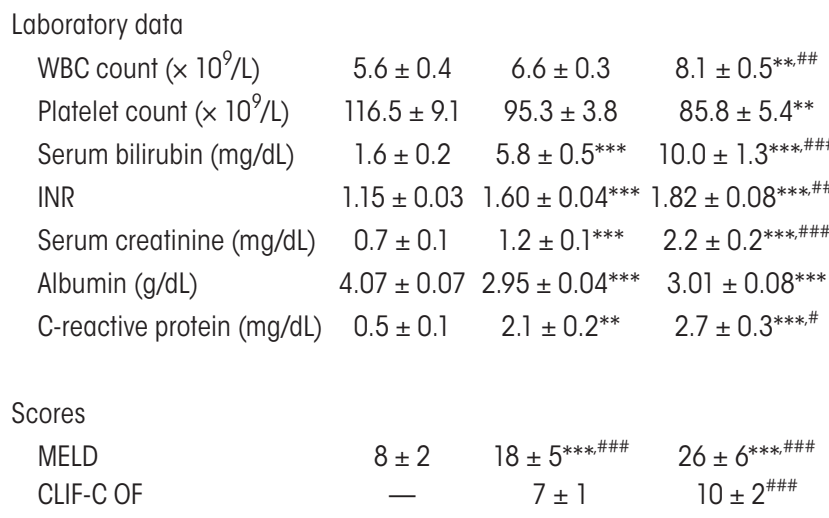

Data are presented as mean \pm SEM or number of patients (percentage).

$P<0.05,{ }^{* *} P<0.005$, and ${ }^{* * *} P<0.001$ for DC or ACLF versus CC; ${ }^{\#} P<0.05,{ }^{\# \#} P<0.005$, and ${ }^{\# \#} P<0.001$ for ACLF versus DC.

Diagnosed by the presence of clinically detectable ascites or surrogates (diuretic treatment, spontaneous bacterial peritonitis, or therapeutic paracentesis prior to or after enrollment).

Abbreviations: CLIF-C OF, CLIF Consortium organ failure; INR, international normalized ratio.

(HCV) were the most common etiologic factors causing liver cirrhosis, although alcohol was more frequent in patients with DC with and without ACLF, whereas $\mathrm{HCV}$ was more common in patients with CC. None of these patients presented infection, alcohol consumption in the last 3 months, or variceal bleeding; therefore, all patients included in this study had an unknown precipitating event(s) for decompensation or ACLF. A similar proportion of patients with diabetes was observed in the DC (44 out of 153) and ACLF 
(23 out of 72) groups. There was a higher proportion of patients with organ failures (liver, kidney, and brain) and ascites in the ACLF group. WBC count, serum bilirubin, creatinine, and $\mathrm{C}$-reactive protein levels and international normalized ratio rose in parallel with the severity of the disease, whereas an inverse relationship was observed in the platelet count. Hypoalbuminemia was present in decompensated patients with and without ACLF. As expected, patients with ACLF showed higher Model for End-Stage Liver Disease (MELD) and CLIF Consortium organ failure scores.

Significant differences were observed among the different groups when albumin was fractionated by
HPLC into the native HMA, HNA1, and HNA2. Specifically, the percentage of the native reduced form (i.e., HMA) was much lower in all patients with cirrhosis compared to healthy controls and was significantly decreased across the different grades of cirrhosis in patients with CC, DC, and ACLF (Fig. 1A). In contrast, the proportion of the oxidized albumin forms (i.e., HNA1 and HNA2) was significantly $(P<0.001)$ increased in patients with cirrhosis with respect to healthy controls (Fig. 1A). In particular, HNA1 markedly increased in patients with CC and $\mathrm{DC}$ and remained elevated to a similar extent in ACLF, while HNA2 showed similar levels in patients
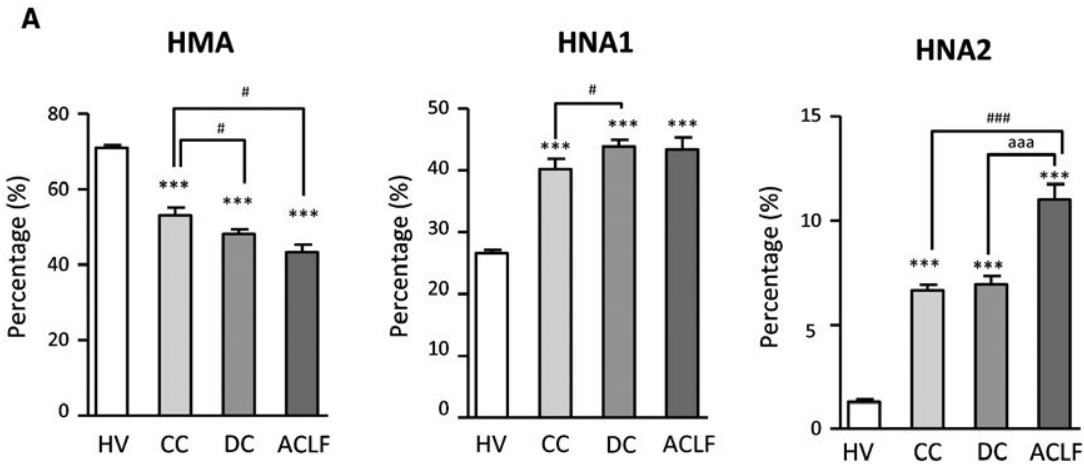

B

IL-6

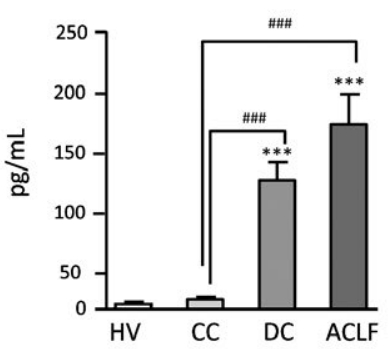

TNF- $\alpha$

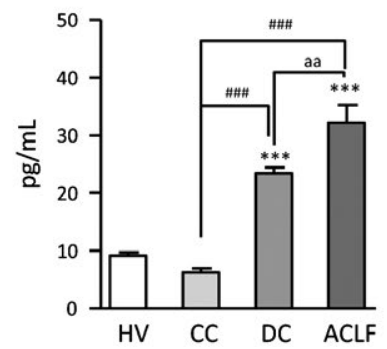

IL-1 $\beta$

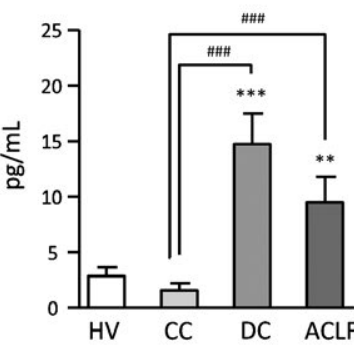

IL-8

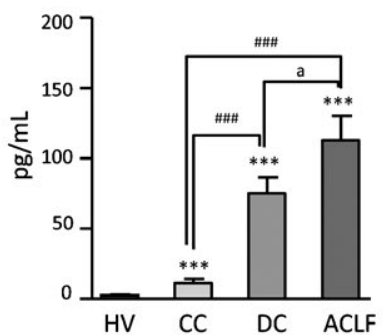

FIG. 1. Relationship between circulating oxidized albumin fractions and cytokines in patients with cirrhosis. (A) Percentage of HMA, HNA1, and HNA2, as determined by HPLC, in plasma from HVs $(\mathrm{n}=48)$, patients with CC $(\mathrm{n}=31)$, patients with DC $(\mathrm{n}=153)$, and patients with ACLF $(n=72)$. (B) Levels of IL-6, IL-1 $\beta$, TNF- $\alpha$, and IL-8, as determined by Luminex technology, in plasma of HVs and patients with cirrhosis. Results are expressed as mean \pm SEM. ${ }^{* *} P<0.005$ and ${ }^{* * *} P<0.001$ for CC, DC, or ACLF versus HV; ${ }^{\#} P<0.05$ and ${ }^{\# \# \#} P<0.001$ for DC or ACLF versus CC; and ${ }^{\mathrm{a}} P<0.05,{ }^{\text {aa }} P<0.005$, and ${ }^{\text {aaa }} P<0.001$ for ACLF versus $\mathrm{DC}$. 
with $\mathrm{CC}$ and $\mathrm{DC}$ and rose sharply in patients with ACLF (Fig. 1A). Supporting Table S2 shows that the pattern of distribution of each albumin fraction in plasma from patients with cirrhosis did not vary notably when patients were divided according to etiology of cirrhosis (alcohol or HCV).

To investigate whether the presence of oxidized albumin forms was related to the degree of systemic inflammation in cirrhosis, we next assessed the plasma concentrations of four well-characterized proinflammatory cytokines: IL-6, IL- $1 \beta$, TNF- $\alpha$, and IL-8. Patients with $\mathrm{CC}$ showed a similar cytokine profile to that of healthy subjects, except for IL-8, with these levels being higher in patients with $\mathrm{CC}$ compared to healthy controls (Fig. 1B). Compared to patients with $\mathrm{CC}$, the DC and ACLF groups showed a pronounced increase in the plasma levels of IL- 6 , IL- $1 \beta$, TNF- $\alpha$, and IL-8 (Fig. 1B). Moreover, TNF- $\alpha$ and IL-8 levels were significantly higher in patients with ACLF than in those with DC (Fig. 1B). Supporting Table S3 shows that the plasma cytokine levels were invariably higher in patients with DC and especially in those with ACLF independently of the etiology of cirrhosis. Spearman correlation analysis identified statistically significant inverse relationships between plasma levels of native albumin (HMA) and IL-1 $\beta, \mathrm{TNF}-\alpha$, and IL-8 (Supporting Table S4). On the contrary, statistically significant direct relationships were seen between plasma levels of HNA1 and IL-1 $\beta$, TNF$\alpha$, and IL- 8 and between HNA2 and IL- 6 and IL- 8 (Supporting Table S4).

In order to test the direct effects of the oxidized forms of albumin in vitro, HNA1 and HNA2 were prepared ex vivo from HMA. Representative deconvoluted chromatographic peaks for HMA, HNA1, and HNA2 obtained by LC-HRMS + qTOF are shown in Fig. 2A. The list of posttranslational modifications of albumin and their relative abundance (percentage) is shown in Table 2. The HMA fraction showed the highest abundance in native albumin isoforms $(70.5 \%)$ with low content of cysteinylated (9.4\%) and sulfinylated (20\%) forms. In contrast, HNA1 mostly contained cysteinylated forms of albumin (79.1\%), including the addition of cysteine by disulfide bridge (59.6\%) and the double cysteinylated and glycated (8.6\%) modifications. HNA2 was rich in higher oxidized isoforms, with the sulfinated $\left(\mathrm{SO}_{2} \mathrm{H}\right.$, $15.9 \%)$ and sulfonated $\left(\mathrm{SO}_{3} \mathrm{H}, 32.1 \%\right)$ albumin being the most abundant (Table 2). HNA2 also contained
$26.1 \%$ of Cys-dehydroalanine-modified albumin, which is the result of the conversion of cysteine 487 into dehydroalanine (Table 2). Consistent with the view that posttranslational modifications of albumin alter its redox activity and its ability to bind ROS, the antioxidant capacity of HNA1 and HNA2 was significantly reduced with respect to native HMA when these albumin forms were assayed at increasing concentrations (Fig. 2B). Moreover, to exclude the possibility of HNA1 and HNA2 acting as a source of oxidative stress inducers, we assessed the release of ROS and RNS by these oxidized albumin forms in a cell-free environment. ROS and RNS release by HNA1 and HNA2 was similar to that of HMA and did not increase in a concentration-dependent manner (Fig. 2C). Finally, to ensure the purity of the ex vivo-prepared HNA1 and HNA2 fractions and the absence of bacterial contaminants, each of the oxidized albumin forms was subjected to the Limulus amebocyte lysate assay in a cell-free system. Trace levels of endotoxin $(<0.17 \mathrm{ng} / \mathrm{mL})$, similar to those present in commercially available low-endotoxin human albumin (for cell culture purposes), were detected in HNA1 and HNA2 fractions as well as in HMA (Fig. 2D). Together, these findings demonstrate that our ex vivo-prepared HNA1 and HNA2 fractions were chemically distinct and free of ROS, RNS, and endotoxin contaminants.

To assess whether HNA1 and HNA2 might play a causative role in systemic inflammation, we tested the effects of these oxidized albumin forms on the production of cytokines by peripheral human leukocytes isolated from HVs. The experiments compared the effects of HNA1 and HNA2 on leukocytes with those of reduced HMA and were carried out at an equal concentration of $1 \mathrm{mg} / \mathrm{mL}$. This concentration was selected as the lowest value of the range of concentrations of oxidized albumins observed in patients with DC (1-3 mg/mL). Figure 3A shows the ability of HNA1, but not HNA2, to evoke a proinflammatory response in human leukocytes. Indeed, a remarkable increase in the production of inflammatory cytokines (i.e., IL-1 $\beta$, IL-6, TNF- $\alpha$, and IL- $1 \alpha$ ) was seen in leukocytes incubated with HNA1. Consistently, increased leukocyte production of anti-inflammatory cytokines (IL-1ra and IL-10), proinflammatory chemokines (IL-8 and MIP-1 $\alpha$ ), and hematopoietic factors (G-CSF and IL-7) was also observed (Fig. 3BD). Interestingly, a gradual increase in the expression 


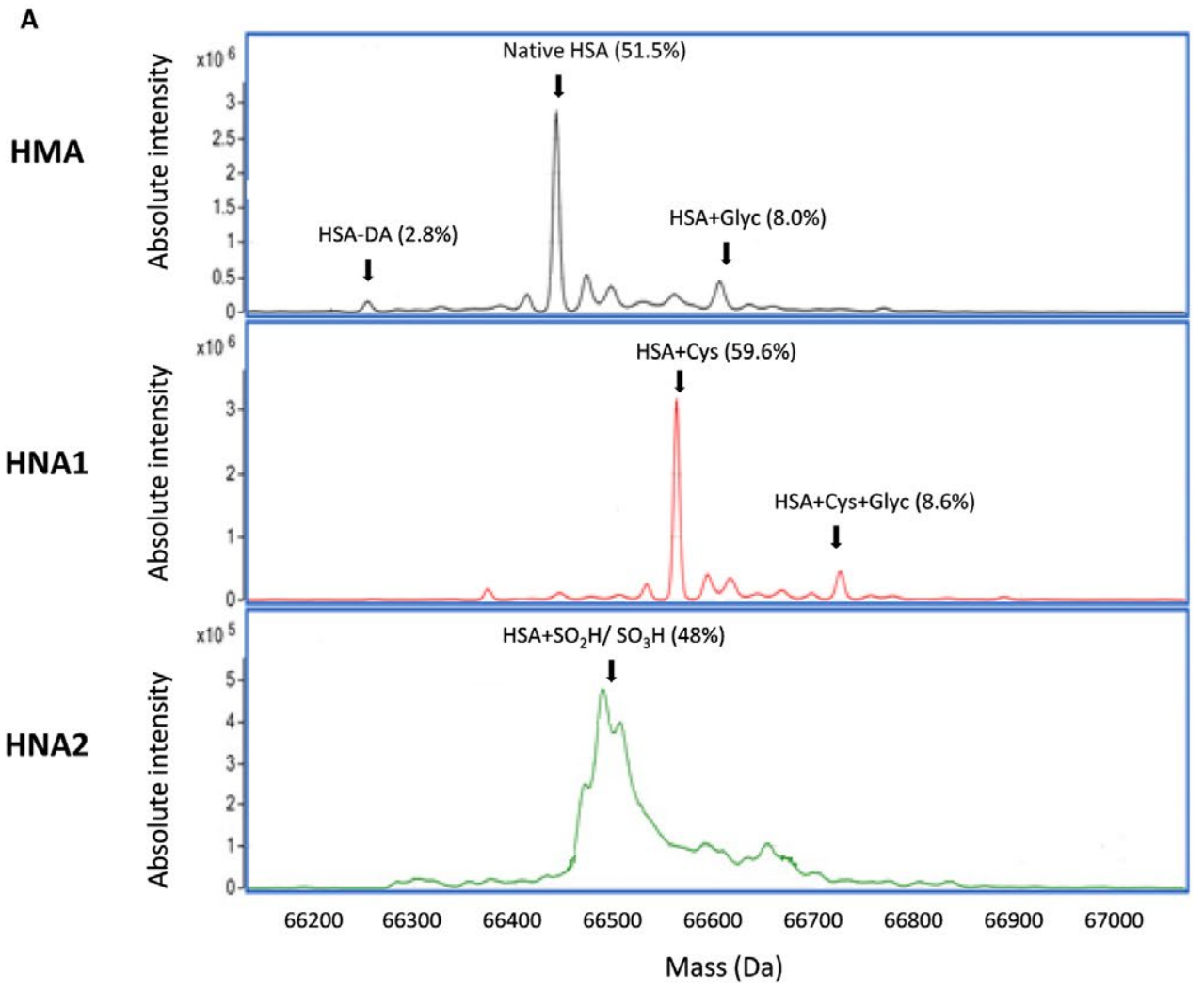

B

Total antioxidant capacity

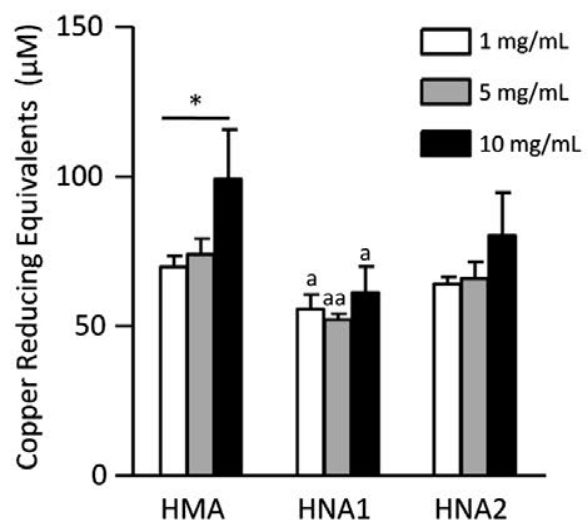

C
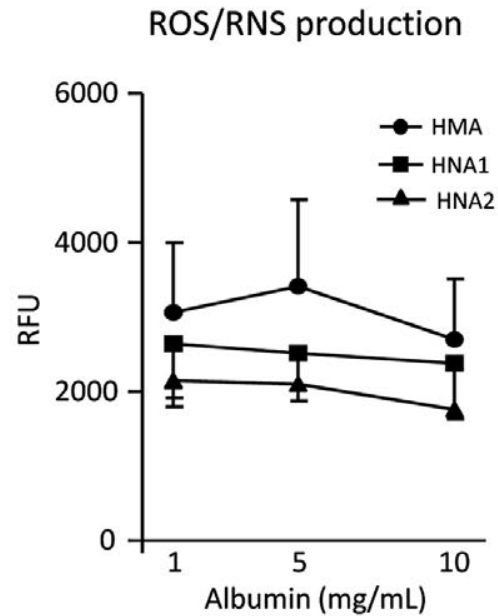

Endotoxin levels

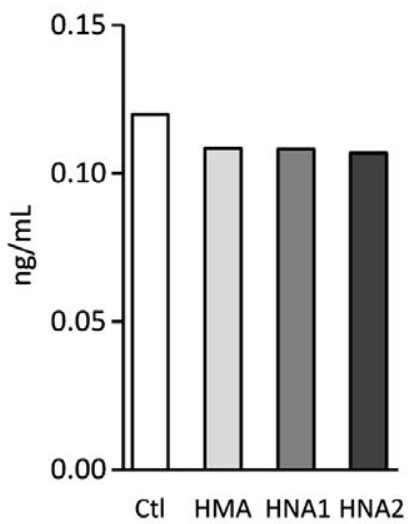

FIG. 2. Characterization of ex vivo-prepared albumin fractions. (A) Representative deconvoluted ESI-MS of oxidized HNA1 (middle panel) and HNA2 (bottom panel) fractions prepared ex vivo from reduced HMA (top panel). Peaks in the spectra represent the various HSA isoforms, in addition to native HSA, carrying the following particular structural alterations: truncation of aspartic acidalanine dipeptide in N-terminal portion (-DA), oxidation of the Cys-34 residue to sulfinic acid $\left(+\mathrm{SO}_{2} \mathrm{H}\right)$ or sulfonic acid $\left(+\mathrm{SO}{ }_{3} \mathrm{H}\right)$, cysteinylation of the Cys-34 residue (+Cys) or glycosylation (+Glyc), and combination of the cysteinylated with the glycosylated form (+Cys+Glyc). (B) Total antioxidant capacity and (C) ROS/RNS production measured at increasing concentrations of HMA, HNA1, and HNA2 in a cell-free environment. Results are expressed as mean \pm SEM of two independent assessments for each albumin fraction in duplicate. ${ }^{*} P<0.05$ for HMA $(1 \mathrm{mg} / \mathrm{mL})$ versus HMA $(10 \mathrm{mg} / \mathrm{mL})$ and ${ }^{\mathrm{a}} P<0.05$ for HNA1 $(1$ or $10 \mathrm{mg} / \mathrm{mL})$ versus HMA $(1 \mathrm{or} 10$ $\mathrm{mg} / \mathrm{mL})$ or ${ }^{\text {aa }} P<0.005$ for HNA1 $(5 \mathrm{mg} / \mathrm{mL})$ versus HMA $(5 \mathrm{mg} / \mathrm{mL})$. (D) Endotoxin levels, determined by the Limulus amoebocyte lysate assay, for HMA, HNA1, and HNA2 compared with those measured in a commercial endotoxin-free $99 \%$ albumin (control). 
TABLE 2. Albumin Fraction Characterization

\begin{tabular}{|c|c|c|c|c|}
\hline \multirow[b]{2}{*}{ Total HSA Isoforms } & \multirow[b]{2}{*}{ Mass (Da) } & \multicolumn{3}{|c|}{ Abundance (\%) } \\
\hline & & HMA & HNAl & HNA2 \\
\hline Native HSA & & $\Sigma=70.5$ & $\Sigma=10.9$ & $\Sigma=5.2$ \\
\hline HSA & 66,440 & 51.5 & 2.1 & 1.9 \\
\hline HSA-DA & 66,255 & 2.8 & 0.3 & 0.0 \\
\hline HSA-L & 66,326 & 1.5 & 0.1 & 0.0 \\
\hline HSA-DA-L & 66,140 & 0.3 & 0.0 & 0.0 \\
\hline $\mathrm{HSA}-\mathrm{DA}+\mathrm{CO}_{2}$ & 66,288 & 0.7 & 0.1 & 1.0 \\
\hline HSA-DHA & 66,408 & 4.4 & 0.6 & 1.2 \\
\hline HSA+Glyc & 66,602 & 8.0 & 6.4 & 0.0 \\
\hline HSA+2Glyc & 66,764 & 1.2 & 1.3 & 1.1 \\
\hline HSA+3Glyc & 66,937 & 0.1 & 0.0 & 0.0 \\
\hline Cysteinylated HSA & & $\Sigma=9.4$ & $\Sigma=79.1$ & $\Sigma=31.7$ \\
\hline HSA-DA+Cys & 66,373 & 0.0 & 3.3 & 1.4 \\
\hline HSA+Cys & 66,558 & 4.7 & 59.6 & 0.0 \\
\hline $\mathrm{HSA}+\mathrm{Cys}+\mathrm{Glyc}$ & 66,719 & 0.9 & 8.6 & 1.3 \\
\hline $\mathrm{HSA}+\mathrm{Cys}+2 \mathrm{Glyc}$ & 66,880 & 0.1 & 0.9 & 0.2 \\
\hline HSA+Cys-DHA & 66,532 & 2.7 & 4.7 & 26.1 \\
\hline $\mathrm{HSA}+\mathrm{Cys}+\mathrm{Glyc}-\mathrm{DHA}$ & 66,691 & 0.8 & 2.0 & 2.5 \\
\hline $\begin{array}{l}\text { HSA+Cys+2Glyc- } \\
\text { DHA }\end{array}$ & 66,846 & 0.2 & 0.0 & 0.0 \\
\hline Sulfinylated HSA & & $\Sigma=20$ & $\Sigma=8.2$ & $\Sigma=61.4$ \\
\hline $\mathrm{HSA}+\mathrm{SO}_{2} \mathrm{H}$ & 66,471 & 9.7 & 1.1 & 15.9 \\
\hline $\mathrm{HSA}+\mathrm{SO}_{3} \mathrm{H}$ & 66,493 & 6.7 & 1.6 & 32.1 \\
\hline $\mathrm{HSA}+\mathrm{SO}_{2} \mathrm{H}+\mathrm{Glyc}$ & 66,629 & 2.0 & 1.9 & 4.9 \\
\hline $\mathrm{HSA}+\mathrm{SO}_{3} \mathrm{H}+\mathrm{Glyc}$ & 66,657 & 1.6 & 3.0 & 7.2 \\
\hline $\mathrm{HSA}+\mathrm{SO}_{3} \mathrm{H}+2 \mathrm{Glyc}$ & 66,820 & 0.0 & 0.5 & 1.1 \\
\hline $\mathrm{HSA}+\mathrm{SO}_{3} \mathrm{H}+3 \mathrm{Glyc}$ & 66,880 & 0.0 & 0.1 & 0.2 \\
\hline
\end{tabular}

Abbreviations: $\mathrm{CO}_{2}$, carboxylation of glutamic acid (+44 Da); Cys, cysteinylation of cysteine by disulfide bridge (addition of cysteine; $+119 \mathrm{Da}$ ); DA, loss of aspartic acid-alanine dipeptide in the $\mathrm{N}$ terminus $(-186 \mathrm{Da})$; DHA, cysteine conversion in dehydroalanine $(-34 \mathrm{Da})$; Glyc, glycosylated; L, loss of leucine in the $\mathrm{C}$ terminus $(-113 \mathrm{Da}) ; \mathrm{SO}_{2} \mathrm{H}$, oxidation of cysteine to sulfinic acid $(+32 \mathrm{Da}) ; \mathrm{SO}_{3} \mathrm{H}$, oxidation of cysteine to sulfonic acid (+48 Da).

of IL-1 $\beta$, IL-6, and TNF- $\alpha$ was seen when HNA1 and HNA2 were combined at increasing ratios within the interval of concentrations present in the circulation of patients with cirrhosis (Fig. 3E).

To identify which leukocyte cell type was more responsive to the inflammatory actions of HNA1, we next tested the albumin fractions on PBMCs and PMNs isolated from healthy donors. The inflammatory response to HNA1 assessed by the induction of inflammatory cytokines (i.e., IL-1 $\beta$, IL-6, and TNF- $\alpha$ ) was more pronounced in PBMCs at both the protein (Fig. 4A) and mRNA (Supporting Fig. $\mathrm{S} 1 \mathrm{~A})$ levels. In contrast, the inflammatory reaction was marginal in PMNs, with HNA1 only inducing a small increase in IL-1 $\beta$ mRNA expression (Fig. 4B). The blunted response of PMNs to HNA1 was confirmed at the protein level because IL-1 $\beta$, IL-6, and $\mathrm{TNF}-\alpha$ were undetectable in the supernatant of these cell incubations (data not shown). Given that the levels of IL-1 $\beta$, IL-6, and TNF- $\alpha$ detected in supernatants from PBMC incubations (Fig. 4A) were 5 -fold to 10 -fold higher than in supernatants from leukocyte incubations (Fig. 3A) and considering that PMNs represent $80 \%$ of the leukocyte population, our findings suggest that mononuclear leukocytes are the main cell target for HNA1 actions. To investigate whether the response to the oxidized albumin isoforms is not different in leukocytes from patients with cirrhosis from that seen in healthy donors, we next replicated the experiments in $\mathrm{PBMCs}$ and $\mathrm{PMN}$ s isolated from patients with DC. Unstimulated PBMCs from patients with cirrhosis showed a higher baseline production of cytokines than those from healthy donors (Fig. 4C). Importantly, compared to $\mathrm{HVs}$, PBMCs from patients with cirrhosis showed a similar pattern of response to oxidized albumins at both the protein (Fig. 4C) and mRNA (Supporting Fig. S1B) levels. Moreover, consistent with that seen in HVs, the response of PMNs from patients with cirrhosis to oxidized albumins was marginal (Fig. 4D).

Biologically active lipid mediators derived from arachidonic acid through the activity of the cyclooxygenase $(\mathrm{COX})$ and lipoxygenase (LOX) pathways also play a major role in systemic inflammation. ${ }^{(18)}$ To confirm that the inflammatory actions of HNA1 were not limited to cytokines, we tested the effects of the oxidized albumin forms on the production of eicosanoids by peripheral human leukocytes isolated from $\mathrm{HVs}$. Figure 5A briefly illustrates the COX-mediated biosynthesis of $\mathrm{PGs}$ and thromboxanes (TXA 2 $\mathrm{TXB}_{2}$ ) and the 5-LOX-mediated formation of $\mathrm{LTB}_{4}$. HNA1 significantly up-regulated the expression of the inducible COX enzyme (i.e., COX-2) and its coordinated terminal microsomal PGE synthase 1 (mPGES-1) (Fig. 5B,C). Expression of the constitutive $\mathrm{COX}$ isoform (i.e., $\mathrm{COX}-1$ ) remained unchanged (Supporting Fig. S2A). Consistent with the induction of COX-2 and mPGES-1, PGE ${ }_{2}$ levels were markedly increased by HNA1 (Fig. 5D). Similarly, PGF $2 \alpha$ and $\mathrm{TXB}_{2}$ were increased by HNA1 (Fig. 5E,F). 

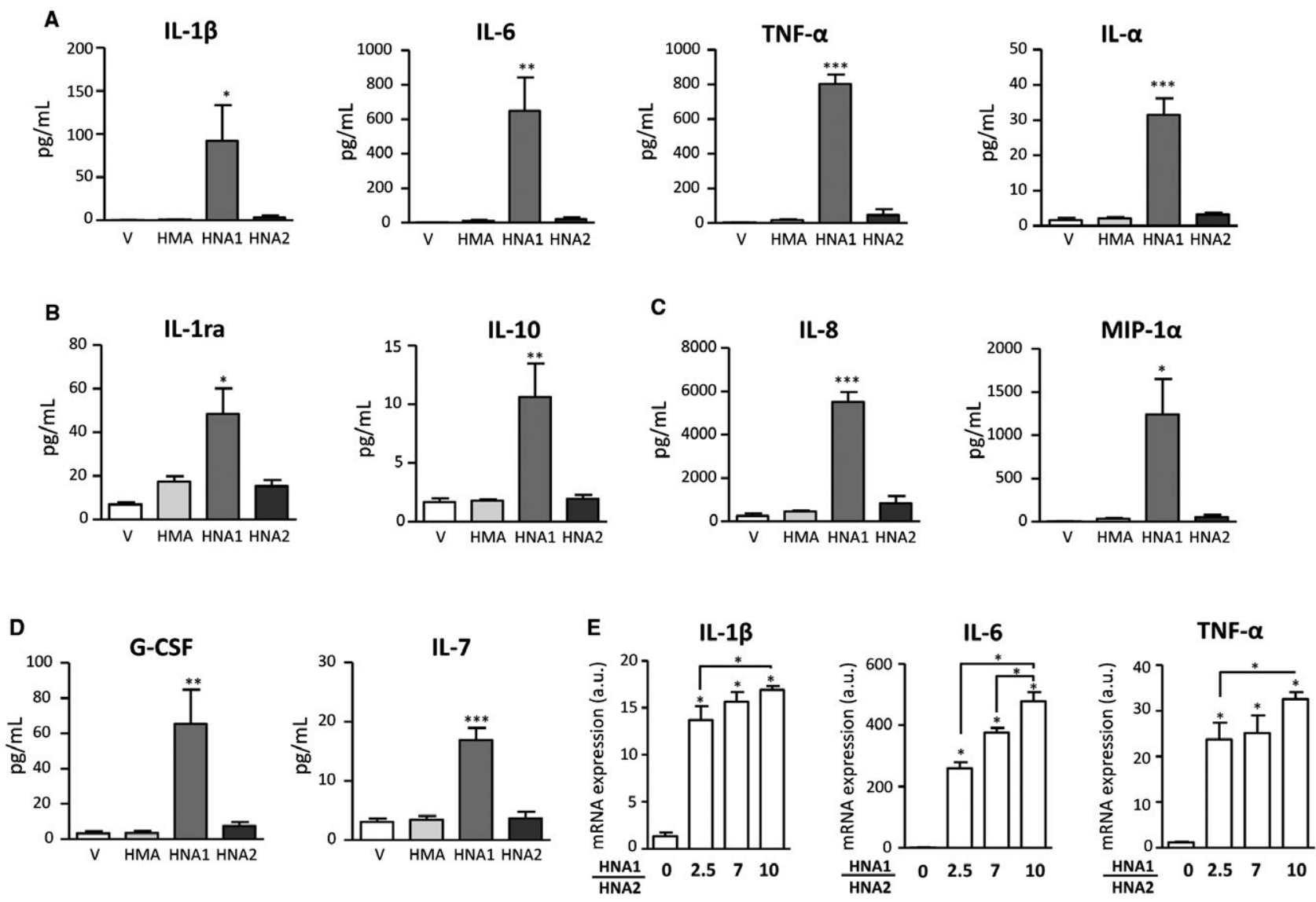

FIG. 3. HNA1 induces a cytokine storm in peripheral human leukocytes. (A-D) Cytokine levels of proinflammatory (IL-1 $\beta$, IL-6, TNF- $\alpha$, and IL-1 $\alpha$ ), anti-inflammatory (IL-1ra and IL-10), chemokines (IL-8 and MIP-1 $\alpha$ ) and hematopoietic factors (G-CSF and IL-7), as determined by Luminex technology, in supernatants of human leukocytes isolated from HVs and incubated with HMA, HNA1, or HNA2 $(1 \mathrm{mg} / \mathrm{mL})$ for 4 hours $\left(\mathrm{n}=5\right.$ in duplicate). Results are expressed as mean $\pm \mathrm{SEM} .{ }^{*} P<0.05,{ }^{* * *} P<0.005$, and ${ }^{* * *} P$ $<0.001$ versus HMA incubation. (E) mRNA expression for IL-1 $\beta$, IL-6, and TNF- $\alpha$, as determined by real-time PCR, in human leukocytes isolated from HVs incubated with increasing proportions of HNA1 versus HNA2 (HNA1/HNA2) to a final concentration of $2 \mathrm{mg} / \mathrm{mL}$ ( $\mathrm{n}=3$ in duplicate). Results are expressed as mean $\pm \mathrm{SEM}^{*} P<0.05$ between each HNA1/HNA2 proportion condition or vehicle (HNA1/HNA2 = 0). Abbreviations: a.u., arbitrary unit; $\mathrm{V}$, vehicle.

Moreover, the potent chemotactic 5-LOX product $\mathrm{LTB}_{4}$ and its pathway marker 5-HETE were significantly stimulated by HNA1 (Fig. 5G,H). Of note, expression of the key enzymes in LT biosynthesis (i.e., 5-LOX, 5-LOX-activating protein, and $\mathrm{LTA}_{4} \mathrm{H}$ ) was not altered by HNA1 (Supporting Fig. S2B-D, suggesting that HNA1 affects not only the expression of the inducible enzymes of the COX pathway but also the release of the common COX and LOX substrate, the polyunsaturated fatty acid arachidonic acid, from the cellular membrane. Interestingly, PBMCs, but not PMNs, from patients with DC responded to HNA1 with a remarkable induction of COX-2 expression (Supporting Fig. S3A,B).
To elucidate which intracellular signaling pathway(s) is triggered when cells are challenged with HNA1, PBMCs were incubated with the different albumin forms, and the phosphorylation of 43 kinases involved in the transduction of inflammatory signals was screened in the Phospho-Kinase Array Kit. A specific profile of kinase phosphorylation was detected in PBMCs incubated with HNA1 (Fig. 6A, left panels). Analysis of the array identified three potential kinases-p38 $\alpha$, AKT, and extracellular signal-regulated kinase (ERK) - in which the phosphorylation signal was at least 2 -fold higher than that of vehicle (Fig. 6A, right panel). Phosphorylation of these three kinases in response to HNA1 was confirmed 

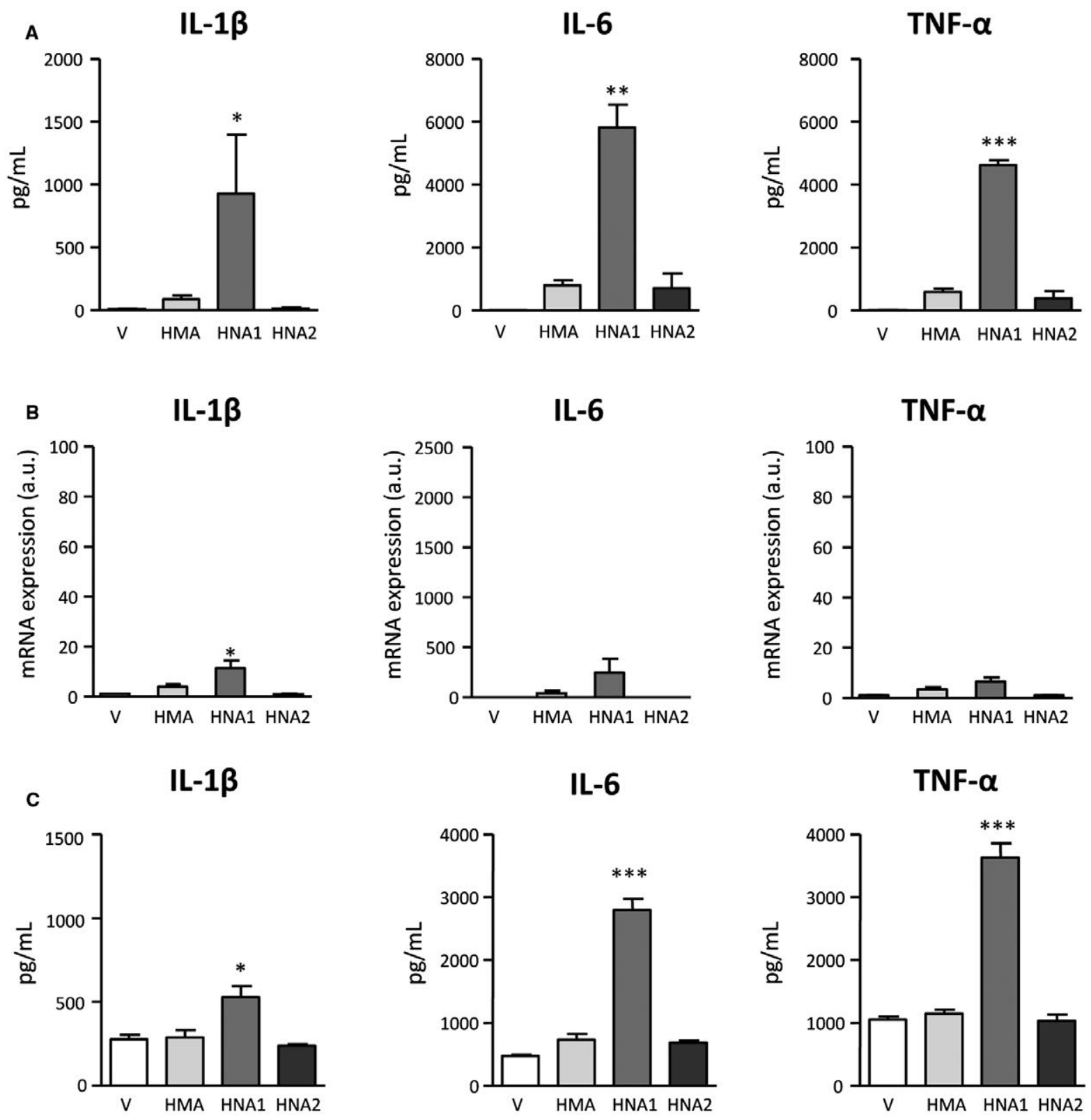

TNF- $\alpha$
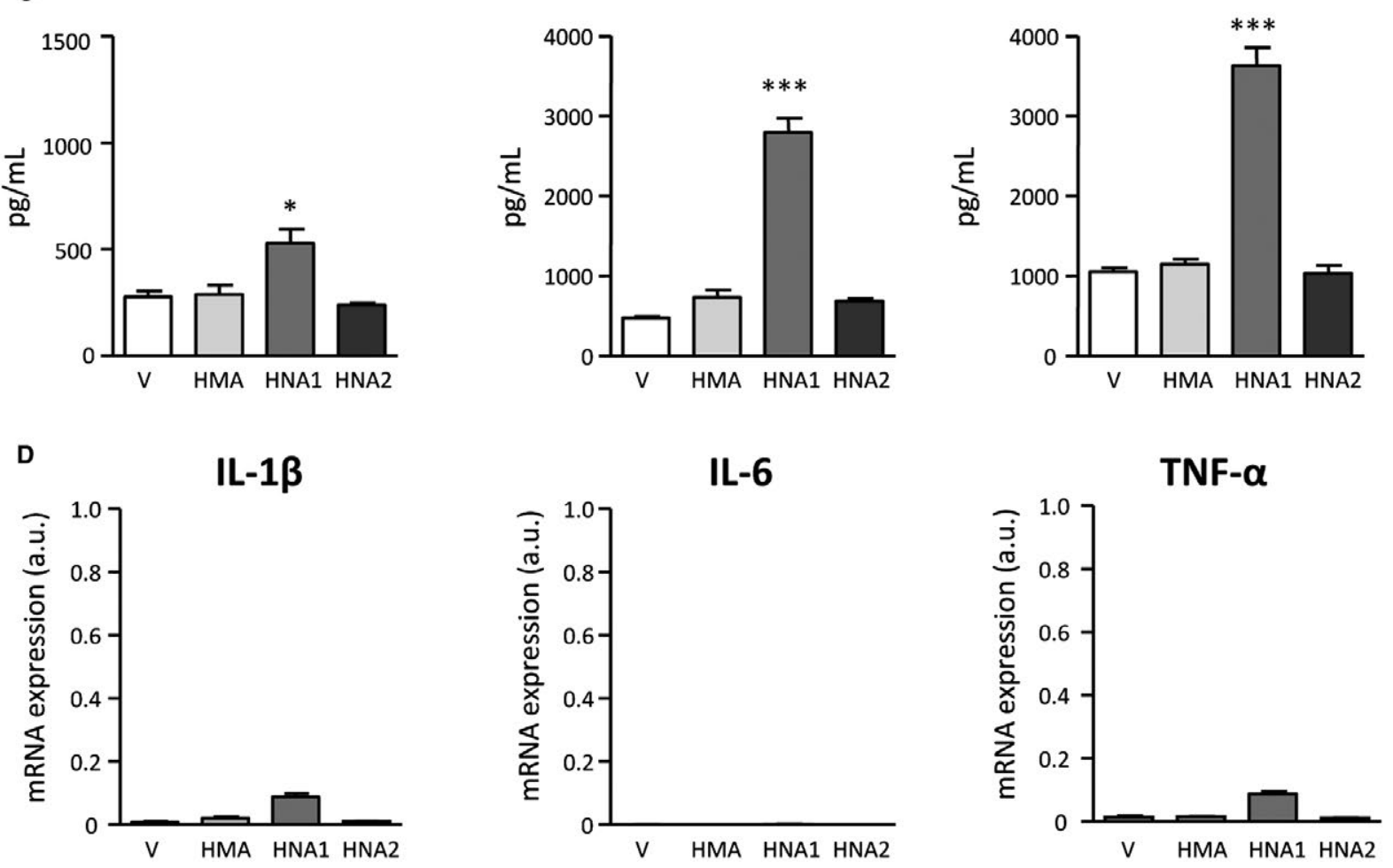
FIG. 4. HNA1 up-regulates cytokine release in human PBMCs. (A) Cytokine levels for IL-1 $\beta$, IL-6, and TNF- $\alpha$ as determined by Luminex technology, in PBMCs isolated from HVs and incubated with HMA, HNA1, or HNA2 (1 mg/mL) for 4 hours $(\mathrm{n}=5$ in duplicate). (B) mRNA expression, as determined by real-time PCR, in PMNs isolated from HVs and incubated with HMA, HNA1, or HNA2 as described above ( $\mathrm{n}=5$ in duplicate). (C) Cytokine levels for IL-1 $\beta$, IL-6, and TNF- $\alpha$ in PBMCs isolated from patients with DC and incubated with HMA, HNA1, or HNA2 ( $\mathrm{n}=3$ in duplicate). (D) mRNA expression in PMNs isolated from patients with DC and incubated with HMA, HNA1, or HNA2 ( $\mathrm{n}=3$ in duplicate). Results are expressed as mean $\pm \mathrm{SEM} .{ }^{*} P<0.05,{ }^{* * *} P<0.005$, and ${ }^{* * *} P<0.001$ versus HMA. Abbreviations: a.u., arbitrary unit; $\mathrm{V}$, vehicle.

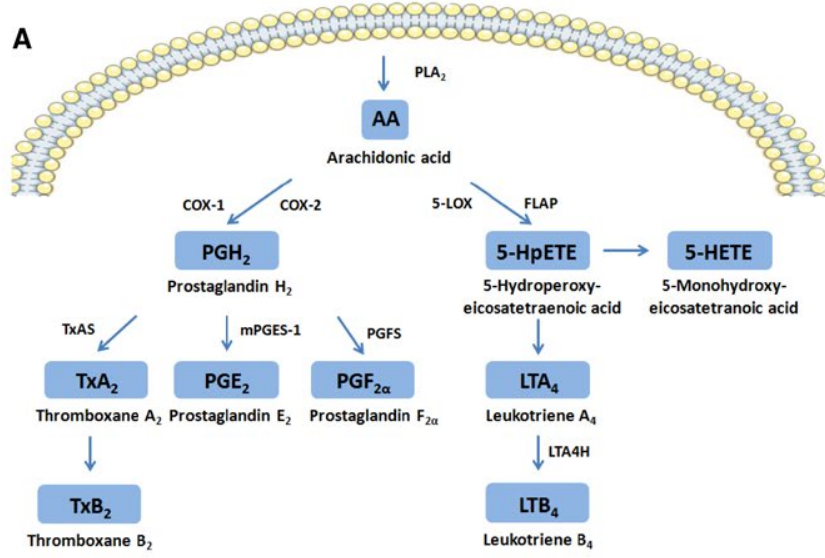

D $\mathrm{PGE}_{2}$

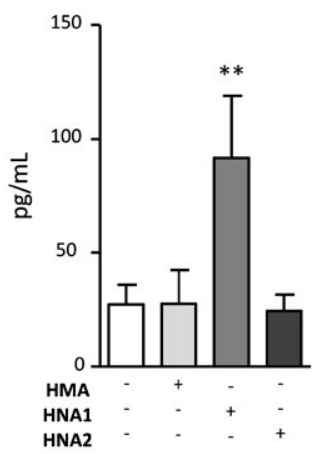

E

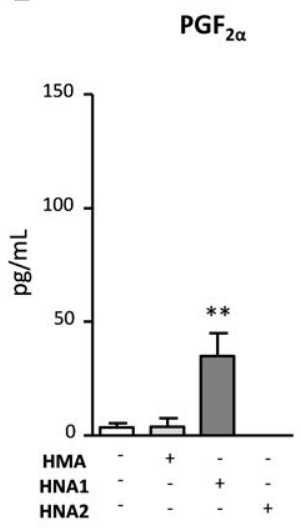

$\mathbf{F}$

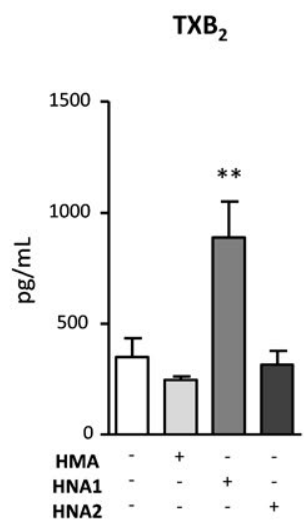

B

cox-2

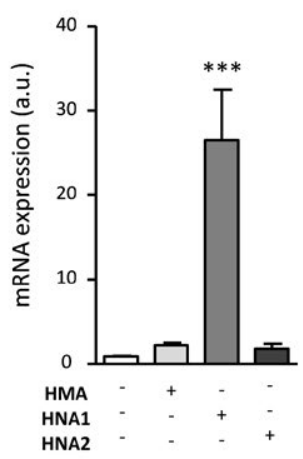

G

$\mathrm{LTB}_{4}$

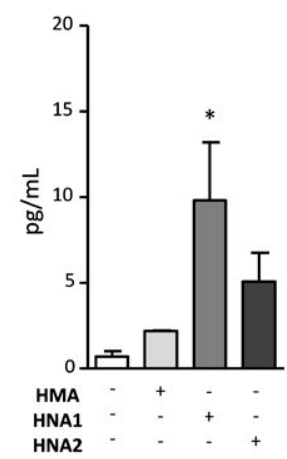

C MPGES-1

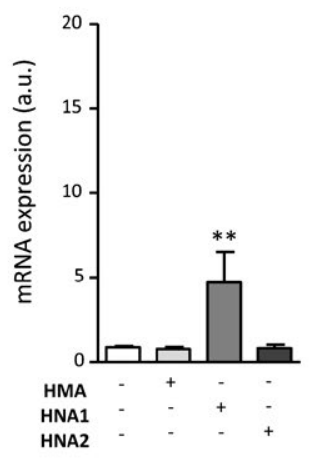

H

5-HETE

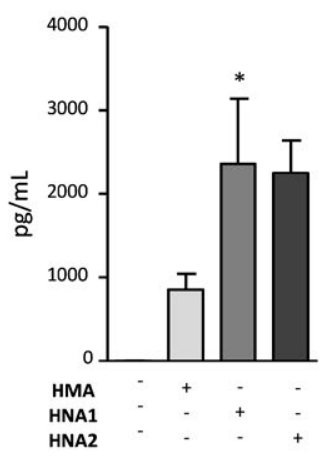

FIG. 5. HNA1 induces an eicosanoid storm in peripheral human leukocytes. (A) Schematic eicosanoid biosynthesis pathways including COX-mediated biosynthesis of $\mathrm{PGs}$ and $\mathrm{TXA}_{2} / \mathrm{TXB}_{2}$ and the 5 -LOX-mediated formation of $\mathrm{LTB}_{4}$. (B,C) mRNA expression for COX-2 and mPGES-1, as determined by real-time PCR, in human leukocytes isolated from HVs and incubated with HMA, HNA1, or HNA2 $(1 \mathrm{mg} / \mathrm{mL})$ for 4 hours $\left(\mathrm{n}=5\right.$ in duplicate). Levels of $(\mathrm{D}-\mathrm{F}) \mathrm{COX}$-derived metabolites $\left(\mathrm{PGE}_{2}, \mathrm{PGF}_{2 \alpha}\right.$, and TXB $\mathrm{T}_{2}$ and $(\mathrm{G}, \mathrm{H})$ 5-LOX-derived metabolites ( $\mathrm{LTB}_{4}$ and 5-HETE), as determined by LC-ESI-MS/MS, in supernatant from human leukocytes isolated from $\mathrm{HV}$ s and incubated under the same conditions as described above. Results are expressed as mean $\pm \mathrm{SEM} .{ }^{*} P<0.05$, ${ }^{* * *} P<0.005$, and ${ }^{* * *} P<0.001$ versus HMA. Abbreviation: a.u., arbitrary unit.

by western blot (Fig. 6B). Time-course experiments identified $\mathrm{p} 38 \alpha$ mitogen-activated protein (MAP) kinase as the most consistent and sustained kinase phosphorylated by HNA1 over time (Fig. 6C). To further confirm the involvement of p38 $\alpha$ MAP kinase in HNA1 actions on PBMCs, we finally incubated these cells in the absence or presence of specific MAP kinase inhibitors. HNA1-induced cytokine production was significantly reduced by incubating PBMCs with the specific p38 $\alpha$ MAP kinase inhibitor SB203580 


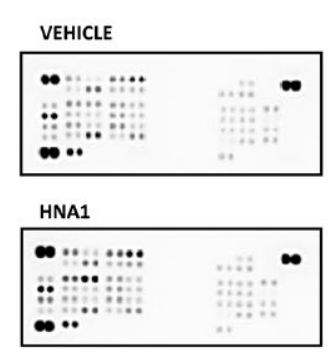

C

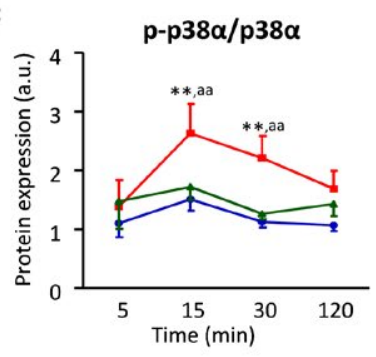

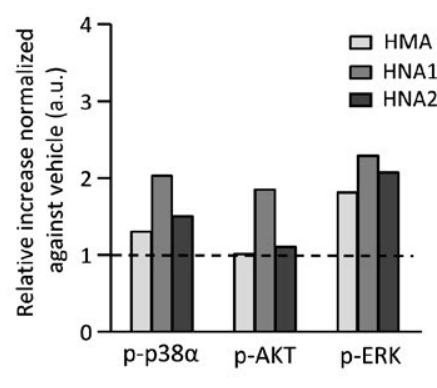

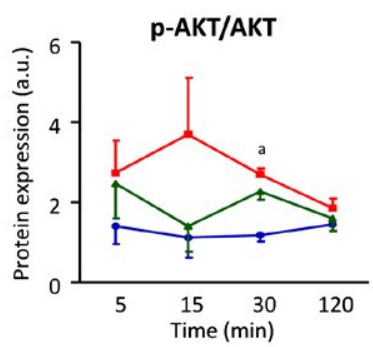

B

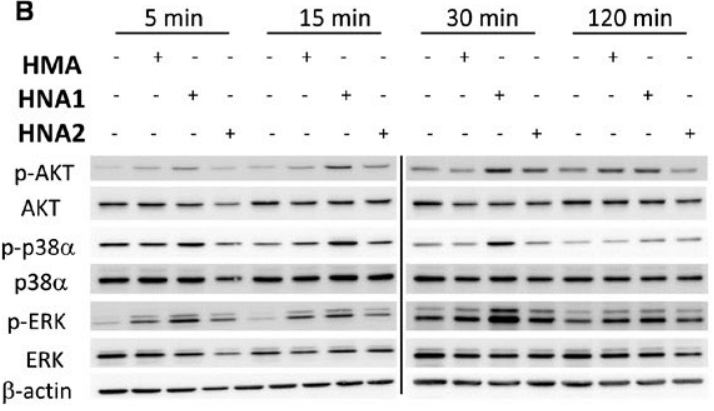

p-ERK/ERK

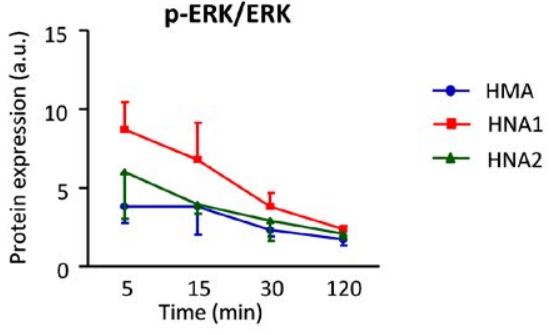

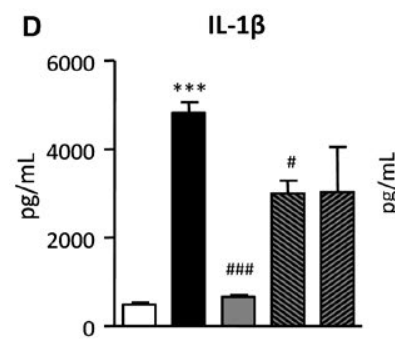
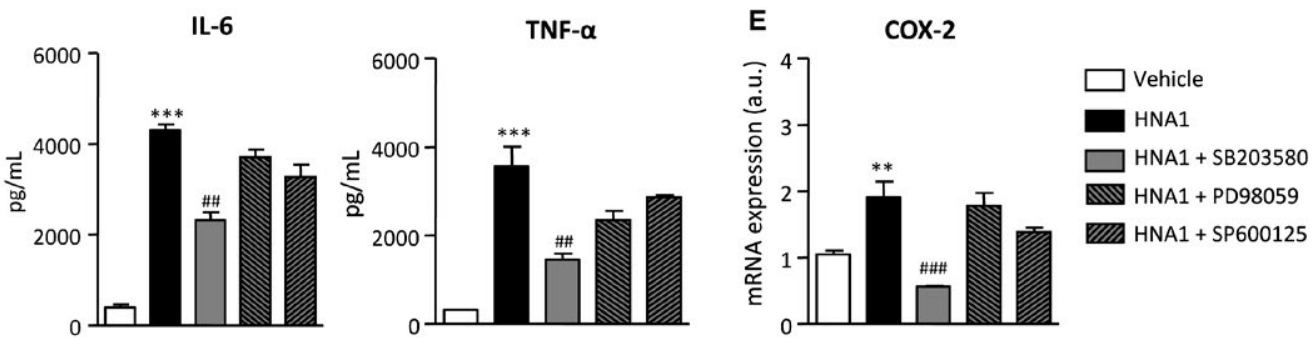

FIG. 6. HNA1 activates human PBMCs through the phosphorylation of p38 $\alpha$ MAP kinase. (A) Representative image of kinase phosphorylation array plots detected in PBMCs incubated with vehicle or HNA1 (left panels) at $1 \mathrm{mg} / \mathrm{mL}$ during 30, 60, or 120 minutes. The densitometric analysis is shown in the right panel. (B) Representative western blot of phosphorylated AKT, p38 $\alpha$, and ERK and total p38 $\alpha$, AKT, and ERK levels in PBMCs isolated from HVs incubated with HMA, HNA1, or HNA2 (1 mg/mL) for 5, 15, 30, or 120 minutes. (C) Kinetic analysis of phosphorylated p38 $\alpha$, AKT, and ERK in PBMCs isolated from HVs incubated with HMA, HNA1, or HNA2 at the same conditions as described above $(n=5)$. Results are expressed as mean \pm SEM. ${ }^{* *} P<0.005$ for HNA1 versus HNA 2 and ${ }^{a} P<0.05$ and ${ }^{\text {aa }} P<0.005$ for HNA1 versus HMA. (D) Levels of proinflammatory cytokines (IL-1 $\beta$, IL-6 and TNF- $\alpha$ ) as determined by Luminex technology, and (E) mRNA expression for COX-2 in PBMCs isolated from HVs incubated in the presence or absence of the $\mathrm{p} 38 \alpha$ inhibitor (SB203580; $5 \mu \mathrm{M})$, MAP kinase kinase 1/2 (ERK pathway) inhibitor (PD98059; $20 \mu \mathrm{M})$, or JNK inhibitor (SP600125; $10 \mu \mathrm{M})$ for 30 minutes before the addition of HNA1 $(1 \mathrm{mg} / \mathrm{mL})$ for 4 hours ( $\mathrm{n}=4$ in duplicate). Results are expressed as mean \pm SEM. ${ }^{* *} P<0.005$ or ${ }^{* * * *} P<0.001$ for HNA1 versus HNA1-untreated cells and ${ }^{\#} P<0.05$, ${ }^{\# \#} P<0.005$, or ${ }^{\# \# \#} P<$ 0.001 for HNA1-stimulated cells versus HNA1-stimulated cells with SB203580, PD98059, or SP600125 pretreatment. Abbreviations: a.u., arbitrary unit; p-, phosphorylated.

(Fig. 6D). In contrast, PD98059 and SP600125, specific inhibitors of MAP kinase kinase 1/2 (upstream ERK kinases) and c-Jun $\mathrm{N}$-terminal kinase (JNK), respectively, were not able to block the inflammatory effects of HNA1 in PBMCs (Fig. 6D). These findings were confirmed at the mRNA level by assessing the expression of COX-2 (Fig. 6E) and IL-1 $\beta$, IL-6, and TNF- $\alpha$ (Supporting Fig. S4).

\section{Discussion}

The pro-oxidant environment present systemically in patients with cirrhosis favors the occurrence of posttranslational modifications of circulating albumin. ${ }^{(7,10,11)}$ In these patients, the two most common modifications are HNA1 and HNA2. HNA1 is a common reversible oxidized albumin that is 
represented by all cysteinylated (mostly HSA-Cys, HSA-DA-Cys, and HSA-Cys-Gly) isoforms. HNA1 has been described to correlate with the MELD score and has been used as a marker of the presence of ascites, renal impairment, and bacterial infection in hospitalized patients with cirrhosis. ${ }^{(9)}$ On the other hand, HNA2, which is an irreversibly oxidized albumin form, includes sulfonylated modifications at Cys34 ( $\mathrm{HSA}-\mathrm{SO}_{2} \mathrm{H}$ and $\mathrm{HSA}-\mathrm{SO}_{3} \mathrm{H}$ ). HNA2 has been related to renal impairment in hospitalized patients with cirrhosis ${ }^{(9)}$ and described as a marker of systemic oxidative stress in patients with DC and ACLF. ${ }^{(1,10)}$ It is important to note that in our study, analysis of the posttranslational modifications of HNA1 and HNA2 produced ex vivo from reduced HMA and characterized by LC-HRMS and qTOF yielded similar results to those reported by Domenicali et al. ${ }^{(9)}$ and Das et al. ${ }^{(19)}$ in HNA1 and HNA2 isolated from the plasma of patients with cirrhosis.

In the current study, we investigated whether, in addition to being markers of oxidative stress in cirrhosis, these two oxidized albumin forms exert any biological effect on the immune system and specifically whether these molecules can induce the activation of peripheral leukocytes. To address this objective and to assess whether oxidized albumin forms may act as inducers of inflammation, and thus as triggers of decompensation and/or ACLF in cirrhosis, we performed our study in a selected cohort of patients with an unknown precipitating event(s). This feature is not uncommon in DC, as revealed by the results of the CANONIC study performed in 1,343 patients recruited across centers from eight different European countries, in whom the origin of the precipitating event was lacking in approximately $50 \%$ of the patients. ${ }^{(2)}$ Our findings provide evidence that increased plasma levels of HNA1 and HNA2 significantly correlated with higher levels of systemic proinflammatory cytokines (i.e., IL-6, IL-1 $\beta$, TNF- $\alpha$, and IL-8) in DC with and without ACLF compared to patients with CC. Therefore, the current results support not only the concept of a close relationship between the levels of oxidized albumin forms and the intensity of systemic inflammation in patients with cirrhosis but also that increased circulating levels of oxidized albumin forms may contribute to precipitating the decompensation of these patients.

A major finding of our study was that, between the two oxidized forms, only HNA1 was able to induce cytokine production in peripheral leukocytes, an effect that was accompanied by the release of potent inflammatory lipid mediators, which are established markers of inflammation. In contrast, the biological activity of HNA2 on human leukocytes was practically null. These findings identify HNA1 as a biologically active form of oxidized albumin that triggers an inflammatory response in peripheral immune cells. Das et al. ${ }^{(19)}$ suggested HNA2 as the biologically oxidized albumin form responsible for the activation of neutrophils in patients with severe alcoholic hepatitis (SAH). There are some points that might help to reconcile these two studies. First, although both studies used neutrophils as an in vitro model, in our study we also tested the biological actions of oxidized albumin on total blood leukocytes and PBMCs from both HVs and patients with cirrhosis. Second, in our study, we prepared the different oxidized albumin fractions ex vivo and tested known quantities of HNA1 and HNA2 in vitro at concentrations seen in patients with cirrhosis. In contrast, Das et al. tested in vitro the effects of albumin isolated from healthy subjects, patients with cirrhosis, and patients with SAH. Because plasma HNA2 levels were higher in patients with SAH than in patients with cirrhosis and healthy subjects and the in vitro effects were more evident in cells treated with albumin from patients with $\mathrm{SAH}$, the authors assumed that the biological effects were due to HNA2. However, the albumin from patients with $\mathrm{SAH}$ contained not only HNA2 (approximately $15.5 \%$ of the total albumin) but also high quantities of HNA1 (44.5\% of the total albumin). ${ }^{(19)}$ Finally, in the current investigation, we used a concentration of $1 \mathrm{mg} / \mathrm{mL}$ of each oxidized albumin form, which is the lowest concentration identified in our cohort of patients with DC. A higher concentration $(16 \mathrm{mg} / \mathrm{mL})$ of albumin fractions was used by Das et al., which corresponds to approximately $4.6 \mathrm{mg} / \mathrm{mL}$ of HNA1 and $1 \mathrm{mg} / \mathrm{mL}$ of HNA2 from plasma obtained from healthy subjects and $7.1 \mathrm{mg} /$ $\mathrm{mL}$ of HNA1 and $2.5 \mathrm{mg} / \mathrm{mL}$ of HNA2 from plasma obtained from patients with SAH. Taken together, our findings provide evidence of the ability of the reversibly oxidized form of albumin, HNA1, to trigger the cytokine and eicosanoid storms in mononuclear leukocytes, while suggesting that the irreversibly oxidized form of albumin, HNA2, is inert in terms of biological activity in leukocytes. Consistent with this view, a recent publication by Magzal et al. demonstrated the proinflammatory effects of HNA1 present 
in serum from hypoalbuminemic patients undergoing dialysis in experiments with human umbilical vein endothelial cells. ${ }^{(20)}$

Another major finding of our study was the identification of the intracellular signaling pathway mediating the inflammatory response of mononuclear cells to HNA1. By screening 43 different kinases involved in the signaling of the inflammatory response in immune cells, we were able to identify p38 MAP kinase as the intracellular signaling pathway mediating the effects of HNA1 on these cells. The involvement of p38 MAP kinase was confirmed using a specific inhibitor of this kinase, which blocked HNA1-induced expression of inflammatory markers. The receptor(s) mediating the activation of $\mathrm{p} 38$ MAP kinase in response to HNA1 was not elucidated in the current study, but a number of potential candidates can be suggested. For example, scavenger receptors (SRs), especially those of class A (SR-A), have the ability to bind large modified serum proteins and to translate the signal through the p38 MAP kinase pathway, although at present there is no evidence that they can bind oxidized albumin. ${ }^{(21)}$ Activation of cluster of differentiation 36, an SR-B linked to p38 MAP kinase signaling by "advanced oxidation protein products," has also been reported. ${ }^{(22)}$ Other SRs, such as glycoproteins 18 and 30, which avidly bind chemically modified albumin by formaldehyde or maleic anhydride, could also be candidates; but they do not signal through p38 MAP kinase. ${ }^{(23)}$ Finally, data based on changes in mRNA expression suggest that up-regulation of several toll-like receptors (TLRs), especially TLR5, could be involved in the response of neutrophils to oxidized albumin forms. ${ }^{(19)}$

Another interesting aspect of our investigation was the confirmation of the proinflammatory actions of HNA1 through the lipidomic analysis of inflammatory mediators released by human leukocytes into the incubation medium. Indeed, LC-MS/MS analysis revealed increased production of inflammatory (i.e., $\mathrm{PGE}_{2}, \mathrm{PGF}_{2 \alpha}$, and $\mathrm{LTB}_{4}$ ) and vasoconstrictor $\left(\mathrm{TXA}_{2}\right)$ eicosanoids in response to HNA1 accompanied by a remarkable up-regulation of enzymes involved in their synthesis, especially the $\mathrm{PGE}_{2}-$ generating enzymes COX-2 and mPGES- 1 . This overproduction of $\mathrm{PGE}_{2}$, which is a pleiotropic $\mathrm{PG}$ released in response to inflammatory stimuli that contributes in a positive loop to the amplification of the initial inflammatory response, ${ }^{(24)}$ is consistent with a prior investigation by O'Brien et al. ${ }^{(25)}$ showing that plasma levels of $\mathrm{PGE}_{2}$ are markedly elevated in patients and experimental animals with DC. In the O'Brien et al. investigation, $\mathrm{PGE}_{2}$ was associated with features of immune suppression (inhibition of TNF- $\alpha$ release by lipopolysaccharide-primed macrophages incubated with plasma from patients with cirrhosis and of bacterial killing capacity in mice with cirrhosis and sepsis). ${ }^{(25)}$ Therefore, one could speculate that high circulating HNA1 levels might also contribute to immune suppression in cirrhosis, which is an important risk factor for bacterial infections in this condition. The mechanism by which HNA1 triggers the production of $\mathrm{PGE}_{2}$ and other eicosanoids by leukocytes is unknown, but perhaps the oxidized albumin form induces the release of arachidonic acid from membrane phospholipids by activating phospholipase $A_{2}$. Indeed, cytosolic free arachidonic acid is readily converted into eicosanoids through the activity of COX and LOX enzymes. ${ }^{(18)}$ Moreover, cytokines such as IL-1 $\beta$ are potent stimuli for COX-2 induction and $\mathrm{PGE}_{2}$ synthesis in an autocrine fashion through the p38 MAP kinase. ${ }^{(26)}$

In summary, our findings offer opportunities for understanding the pathophysiological processes underlying systemic inflammation in cirrhosis. Our findings also support the concept that the transition from $\mathrm{CC}$ to $\mathrm{DC}$ in patients without an identifiable precipitating event occurs in parallel with a sharp increase in the degree of systemic inflammation. This view coincides with our data showing that circulating levels of the oxidized albumin form HNA1 were higher in patients with $\mathrm{AD}$ but without ACLF than in those who were compensated, suggesting that HNA1 actively participates in the systemic inflammatory response that leads patients with cirrhosis to decompensation. Finally, our data demonstrating that oxidized albumin has biological properties and induces the activation of peripheral immune cells provide a solid argument for the removal of oxidized albumin from the plasma of patients with advanced liver disease and its replacement with reduced albumin through interventional approaches such as plasma exchange. ${ }^{(27,28)}$ Alternatively, patients with advanced liver disease could benefit from therapies promoting an antioxidant environment that may induce the conversion of HNA1 into HMA.

Acknowledgment: This study was carried out at the Center Esther Koplowitz. We are indebted to Anabel 
Martínez-Puchol for her technical assistance. We also thank Dr. Pol Herrero (Centre for Omics Sciences of the Universitat Rovira i Virgili, Reus, Spain) and Dr. Michael Rothe (Lipidomix GmbH, Berlin, Germany) for his expertise in MS.

\section{REFERENCES}

1) Clària J, Stauber RE, Coenraad MJ, Moreau R, Jalan R, Pavesi $\mathrm{M}$, et al. CANONIC study investigators of the EASL-CLIF Consortium and the European Foundation for the Study of Chronic Liver Failure (EF-CLIF). Systemic inflammation in decompensated cirrhosis: characterization and role in acute-onchronic liver failure. Hepatology. 2016;64:1249-1264.

2) Moreau R, Jalan R, Gines P, Pavesi M, Angeli P, Cordoba J, et al. Acute-on-chronic liver failure is a distinct syndrome that develops in patients with acute decompensation of cirrhosis. Gastroenterology. 2013;144:1426-1437.

3) Bernardi J, Moreau R, Angeli P, Schnable B, Arroyo V. Mechanism of decompensation and organ failure in cirrhosis: from peripheral arterial vasodilation to systemic inflammation hypothesis. J Hepatol. 2015;63:1272-1284.

4) Gustot T, Fernández J, García E, Morando F, Caraceni P, Alessandria $\mathrm{C}$, et al. Clinical course of acute-on-chronic liver failure syndrome and effects on prognosis. Hepatology. 2015;62:243-252.

5) Arroyo V, Moreau R, Kamath PS, Jalan R, Ginès P, Nevens F, et al. Acute-on-chronic liver failure in cirrhosis. Nat Rev Dis Primers. 2016;2:16041.

6) Garcia-Martinez R, Caraceni P, Bernardi M, Gines P, Arroyo V, Jalan R. Albumin: pathophysiologic basis of its role in the treatment of cirrhosis and its complications. Hepatology. 2013;58:1836-1846.

7) Arroyo V, García-Martinez R, Salvatella X. Human serum albumin, systemic inflammation, and cirrhosis. J Hepatol. 2014;61:396-407.

8) Sort P, Navasa M, Arroyo V, Aldeguer X, Planas R, Ruiz-delArbol L, et al. Effect of intravenous albumin on renal impairment and mortality in patients with cirrhosis and spontaneous bacterial peritonitis. N Engl J Med. 1999;341:403-409.

9) Domenicali M, Baldassarre M, Giannone FA, Naldi M, Mastroroberto M, Biselli M, et al. Posttranscriptional changes of serum albumin: clinical and prognostic significance in hospitalized patients with cirrhosis. Hepatology. 2014;60:1851-1860.

10) Oettl K, Birner-Gruenberger R, Spindelboeck W, Stueger HP, Dorn L, Stadlbauer V, et al. Oxidative albumin damage in chronic liver failure: relation to albumin binding capacity, liver dysfunction and survival. J Hepatol. 2013;59:978-983.

11) Oettl K, Stadlbauer V, Petter F, Greilberger J, Putz-Bankuti C, Hallström S, et al. Oxidative damage of albumin in advanced liver disease. Biochim Biophys Acta. 2008;1782:469-473.

12) Kawai K, Yoh M, Hayashi T, Imai $H$, Negawa T, Tomida $M$, et al. Effect of diabetic retinopathy on redox state of aqueous humor and serum albumin in patients with senile cataract. Tokai J Exp Clin Med. 2001;26:93-99.

13) Naldi M, Giannone FA, Baldassarre M, Domenicali $M$, Caraceni $P$, Bernardi M, et al. A fast and validated mass spectrometry method for the evaluation of human serum albumin structural modifications in the clinical field. Eur J Mass Spectrom. 2013;19:491-496.
14) Martínez-Acedo P, Núñez E, Gómez FJ, Moreno M, Ramos E, Izquierdo-Álvarez A, et al. A novel strategy for global analysis of the dynamic thiol redox proteome. Mol Cell Proteomics. 2012;11:800-813.

15) Murray CI, Van Eyk JE. Chasing cysteine oxidative modifications: proteomic tools for characterizing cysteine redox status. Circ Cardiovasc Genet. 2012;5:591.

16) Bar-Or R, Rael LT, Bar-Or D. Dehydroalanine derived from cysteine is a common post-translational modification in human serum albumin. Rapid Commun Mass Spectrom. 2008;22:711-716.

17) Alcaraz-Quiles J, Titos E, Casulleras M, Pavesi M, LópezVicario C, Rius B, et al. Polymorphisms in the IL-1 gene cluster influence systemic inflammation in patients at risk for acute-onchronic liver failure. Hepatology. 2017;65:202-216.

18) Dennis EA, Norris PC. Eicosanoid storm in infection and inflammation. Nat Rev Immunol. 2015;15:511-523.

19) Das S, Maras JS, Hussain MS, Sharma S, David P, Sukriti S, et al. Hyperoxidized albumin modulates neutrophils to induce oxidative stress and inflammation in severe alcoholic hepatitis. Hepatology. 2017;65:631-646.

20) Magzal F, Sela S, Szuchman-Sapir A, Tamir S, Michelis R, Kristal B. In-vivo oxidized albumin - A pro-inflammatory agent in hypoalbuminemia. PLoS One. 2017;12:e177799.

21) Canton J, Neculai D, Grinstein S. Scavenger receptors in homeostasis and immunity. Nat Rev Immunol. 2013;13:621-634.

22) Marsche G, Frank S, Hrzenjak A, Holzer M, Dirnberger S, Wadsack C, et al. Plasma-advanced oxidation protein products are potent high-density lipoprotein receptor antagonists in vivo. Circ Res. 2009;104:750-757.

23) Schnitzer JE, Sung A, Horvat R, Bravo J. Preferential interaction of albumin-binding proteins, gp30 and gp18, with conformationally modified albumins. Presence in many cells and tissues with a possible role in catabolism. J Biol Chem. 1992;267:24544-24553.

24) Aoki T, Narumiya S. Prostaglandins and chronic inflammation. Trends Pharmacol Sci. 2012;33:304-311.

25) O'Brien AJ, Fullerton JN, Massey KA, Auld G, Sewell G, James $\mathrm{S}$, et al. Immunosuppression in acutely decompensated cirrhosis is mediated by prostaglandin E2. Nat Med. 2014;20:518-523.

26) Guan Z, Buckman SY, Miller BW, Springer LD, Morrison AR. Interleukin-1beta-induced cyclooxygenase-2 expression requires activation of both c-Jun NH2-terminal kinase and p38 MAPK signal pathways in rat renal mesangial cells. J Biol Chem. 1998;273:28670-28676

27) Artigas A, Wernerman J, Arroyo V, Vincent JL, Levy M. Role of albumin in diseases associated with severe systemic inflammation: pathophysiologic and clinical evidence in sepsis and in decompensated cirrhosis. J Crit Care. 2016;33:62-70.

28) Oettl K, Stadlbauer V, Krisper P, Stauber RE. Effect of extracorporeal liver support by molecular adsorbents recirculating system and Prometheus on redox state of albumin in acute-on-chronic liver failure. Ther Apher Dial. 2009;13:431-436.

Author names in bold designate shared co-first authorship.

\section{Supporting Information}

Additional Supporting Information may be found at onlinelibrary.wiley.com/doi/10.1002/hep.30135/suppinfo. 